\title{
Persistent negative symptoms in schizophrenia: survey of Canadian psychiatrists
}

\author{
Danyael Lutgens, ${ }^{1}$ Martin Lepage, ${ }^{2}$ Rahul Manchanda ${ }^{3}$ and Ashok Malla ${ }^{4}$
}

${ }^{1} \mathrm{PhD}$ Candidate, McGill University Department of Psychiatry; Prevention and Early Intervention Program for the Psychoses, Douglas Mental Health University Institute, Montreal, Quebec, Canada

${ }^{2}$ Associate Professor, Department of Psychiatry, McGill University, Montreal, Quebec: Prevention and Early Intervention Progam for thary Intervention Program for the Psychoses, Douglas Mental Health University Institute, Montreal, Quebec, Canada

3Professor, Department of Psychiatry, Western University, Ontario; Medical Director, Prevention and Early Intervention Program for the Psychoses, London Health Sciences Centre, London, Ontario, Canada

4Professor, Department of Psychiatry, McGill University, Montreal, Quebec: Director, Prevention and Early Intor, Prevention and Early Inter, Program for the Psychoses,
Douglas Mental Health University Institute, Montreal, Quebec, Canada, email ashok.malla@ douglas.mcgill.ca

This survey was conducted with support from Roche Canada. The work reported here is funded through a grant from Canadian Institutes of Health Research (CIHR) to Dr Ashok Malla and Malla an colleagues. Danyael Lutgens is supported through a CIHR graduate scholarship fund and Dr Malla is funded by the Canada Research Chairs programme of the CIHR.
A sample of 206 Canadian psychiatrists who routinely treat patients with psychotic disorders were randomly surveyed regarding their knowledge and practice in relation to persistent negative symptoms of schizophrenia. Large majorities reported observing a high prevalence of persistent negative symptoms that do not respond to available treatments ( $83 \%$ ), have a profound impact on functional outcomes (96.5\%) and contribute to family burden. Almost half the sample (43\%) recognised the importance of formally assessing persistent symptoms and nearly a third $(30 \%)$ indicated that this was a part of their usual practice. These survey results correspond with recent consensus and highlight the importance and challenge of treating persistent negative symptoms in schizophrenia.

Negative symptoms, a distinct domain of schizophrenia, represent a fundamental challenge to treatment protocols (Kirkpatrick et al, 2006). This cluster of symptoms, comprising affective flattening, poverty of thought, anhedonia/asociality, avolition and poor motivation (Andreasen \& Olsen, 1982), is conceptualised as either primary deficits (core deficits of schizophrenia) or secondary deficits - resulting either as medication side-effects or from other symptoms such as depression (Möller, 2003). These symptoms are present in a majority of patients during their first episode of psychosis (Malla et al, 2002). A smaller proportion $(20-30 \%)$ have sustained primary negative symptoms that are defined as persistent negative symptoms (Buchanan, 2007). The importance of treating negative symptoms is highlighted by their strong association with quality of life (BowThomas et al, 1999), social functioning (Corcoran et al, 2011), interpersonal relationships, work performance and overall functional outcomes (Milev et al, 2005); they are also of great importance to carers and contribute to community burden (Perlick et al, 2006).

Despite the serious implications of negative symptoms, few effective pharmacological treatments are available for primary negative symptoms, which, therefore, tend to persist (Malla et al, 2002). According to expert consensus, clinical recognition and understanding of negative symptoms is the first step in improving functional outcomes (Malla et al, 2002). However, the often insidious and relatively complex nature of negative symptoms
(Kirkpatrick et al, 2006), lack of adequate pharmacological treatment (Malla et al, 2002), possible benefit from psychosocial interventions (Barnes \& Paton, 2011) and the potential for new treatment discoveries highlight the importance of current physician perspectives, knowledge and practices. The aim of this pilot study was to explore broadly how Canadian psychiatrists who regularly treat patients with psychotic disorders conceptualise, evaluate and treat persistent negative symptoms in schizophrenia in the light of recent developments in this field. No a priori hypothesis was considered.

\section{Method}

Psychiatrists listed in the Canadian Medical Directory, including those from the Canadian Psychiatric Association and Association des Médecins de Psychiatres du Québec (which have a combined total of 3500 registered members), were contacted to ask for their participation in a survey on negative symptoms if they routinely treated patients with a psychosis. They were given the option of participation via a secure website or by post (with a paper copy). Two hundred and six agreed to participate: $127(62 \%)$ by post and 79 online $(38 \%)$.

Ethical approval for the study was obtained from the Douglas Mental Health University Institute.

The questionnaire for the study was designed by the investigators to obtain psychiatrists' perspectives on persistent symptoms in schizophrenia as seen in their clinical practice. There were 13 questions regarding knowledge of negative symptoms and several items relating to persistent positive symptoms (the latter are not included here, given the scope of this report). The questions concerned: negative symptoms and potential confounds such as extrapyramidal symptoms and depression; level of awareness; the efficacy of treatment options; the relevance of such symptoms for functional outcomes; and their effect on carers. Each item was scored on a five-point Likert scale. Details of the survey instrument are available upon request from the authors.

Simple frequencies were computed for physician demographics and responses using Statistical Package for the Social Sciences (SPSS, version 18).

\section{Results}

Respondents came from a range of settings and indicated an average of 21 years in practice (s.d. $12.64, n=179)$. More than half of all respondents were male $(60 \%, n=124)$. Their mean age was 53 (s.d. 12.75, $n=188)$. 


\section{Frequency and visibility of symptoms}

Comparatively large proportions of psychiatrists reported observing asociality $(n=92,46 \%)$, avolition $(n=91,45 \%)$ and flat affect $(n=71,36 \%)$ 'very frequently' (i.e. in $50-74 \%$ of patients) in patients with psychotic disorders in their clinical practice. Anhedonia and alogia were rated as being seen 'frequently' (25-49\% of patients) by $89(44 \%)$ and $72(36 \%)$, respectively. Specifically in first-episode psychosis (FEP), the prevalence of negative symptoms was rated at $25-49 \%$ of patients by 93 psychiatrists (46\%). Respondents largely 'agreed' or 'strongly agreed' that they could distinguish between negative symptoms and overlapping symptoms (e.g. extrapyramidal symptoms and depression) ( $n=150,76 \%$ ) (for complete responses, see Table 1$)$.

\section{The impact of persistent symptoms}

A large majority of psychiatrists $(n=142,71 \%)$ rated the contribution of negative symptoms to functioning as 'very important' and an additional $51(26 \%)$ reported this relationship to be 'important'. Similarly, a large majority of psychiatrists $(n=179 ; 90 \%)$ indicated that negative symptoms were 'frequently' or 'always' a burden to carers. Avolition/apathy was rated as the largest burden by $148(89 \%)$ psychiatrists.

A large number of psychiatrists endorsed the statement 'positive symptoms can lead to persistent negative symptoms' ('agree'; $n=81,40 \%$ ), while a smaller number $(n=71,35 \%)$ were undecided about this. For complete responses, see Table 1.

\section{Treatment of negative symptoms}

Only $13.5 \%$ of respondents $(n=27)$ rated secondgeneration antipsychotics as 'effective' (in $50-74 \%$ of patients) or very effective $(n=5,3 \%)$. Psychiatrists rated antidepressants as being 'ineffective' ( $n=95,48 \%$; effective in only $11-24 \%$ of patients), or 'somewhat effective' $(n=86,43 \% ; 25-49 \%$ of patients) in treating negative symptoms. A large number of psychiatrists $(n=119,60 \%)$ rated cognitive-behavioural therapy (CBT) as 'somewhat effective' (of benefit for 25-49\% of patients) in the treatment of negative symptoms but only a minority $(n=33,17 \%)$ rated it as being 'effective' or 'very effective'. For complete responses, see Table 2.

\section{Discussion}

Given the implications of persistent negative symptoms and the difficulty in treating them, knowledge of the issue is imperative for clinicians in the field. Our survey findings corroborate recent consensus guidelines (Kirkpatrick et al, 2006) and suggest that the responding Canadian psychiatrists in this study see negative symptoms in psychosis as widely prevalent, resistant to treatment and of great consequence for functional outcomes in patients with psychotic disorders. This is generally in agreement with findings from both epidemiological (Malla $e t$ $a l, 2002$ ) and clinical studies (Malla et al, 2011).

Our survey data indicate that the majority of psychiatrists consider persistent negative symptoms in psychosis to have an impact on functional outcomes and to increase carer burden, especially in relation to the domain of avolition/apathy. The high endorsement of the relationship between negative symptoms and functional outcome is supported by research findings (Milev et al, 2005).

Interestingly, half of the responding psychiatrists $(50 \%)$ 'agreed' or 'strongly agreed' that persistent positive symptoms were a problem because of their effect on negative symptoms. This view is consistent with recent characterisations of the longitudinal relationships between symptoms, and emphasises the importance of monitoring secondary negative symptoms when positive symptoms worsen (Möller, 2007). Further, this may also reflect a belief psychiatrists hold that persistent positive symptoms lead to increases in negative symptoms over time, possibly due to some unknown toxicity. Such a hypothesis has been suggested in relation to the effects of prolonged duration of untreated psychosis (Malla et al, 2011).

Only a minority of this sample of psychiatrists regarded antipsychotics (16\%) or CBT (18\%) as an effective treatment for negative symptoms. This view of antipsychotics is likely based on clinical experience. Antidepressants were rated by virtually all psychiatrists as being at best somewhat effective in the treatment of negative symptoms. While antidepressants may work in treating negative symptoms secondary to depression, they have been shown to be largely ineffective with persistent negative symptoms (Barnes \& Paton, 2011). This perspective is consistent with research evidence (Malla et al, 2002). It would, therefore, appear that this sample of psychiatrists no longer accept that second-generation antipsychotics are likely to be effective in treating negative symptoms. Possibly this is also related to the psychiatrists' reported clinical ability to distinguish secondary from primary negative symptoms. The overall ability of clinicians to discriminate among symptoms lends clinical validity to evidence that negative symptoms in psychosis are a unique and independent construct that may now be better measured (Foussias et al, 2009; Cassidy et al, 2012), and that can be specifically targeted for treatment if effective treatments were to become available (Malla et al, 2002).

The level of experience psychiatrists have with the use of CBT is unknown but is anyway likely to be less than with the use of antipsychotic medication. CBT is reported to be somewhat more promising than antipsychotic or antidepressant medications (Rector \& Beck, 2001; Wykes et al, 2008). The utility of CBT, however, may be undermined in particular contexts. Moreover, CBT for negative symptoms is not widely available and is traditionally provided over relatively long periods of time. Further, CBT may not be appropriate for all patients, depending on their level of functioning (Lehman et al, 2004).

Our results likely represent the opinion of only those psychiatrists who frequently treat patients with psychotic disorders and who volunteered to participate. The selection may well have been 
Table 1

Frequency, visibility and impact of symptoms: $n(\%)$

\begin{tabular}{|c|c|c|c|c|c|}
\hline $\begin{array}{l}\text { How often do you see the following negative symptoms in your } \\
\text { patients? }\end{array}$ & $\begin{array}{l}\text { Almost always } \\
\text { (>75\% of patients) }\end{array}$ & $\begin{array}{l}\text { Very frequently } \\
(50-74 \%)\end{array}$ & $\begin{array}{l}\text { Frequently } \\
(25-49 \%)\end{array}$ & $\begin{array}{l}\text { Occasionally } \\
(11-24 \%)\end{array}$ & Rarely $(<10 \%)$ \\
\hline Asociality & $30(15 \%)$ & $92(46 \%)$ & $61(30 \%)$ & $12(6 \%)$ & $6(3 \%)$ \\
\hline Avolition & $44(22 \%)$ & $91(45 \%)$ & $46(23 \%)$ & $14(7 \%)$ & $6(3 \%)$ \\
\hline Anhedonia & $13(7 \%)$ & $64(32 \%)$ & $89(44 \%)$ & $29(14 \%)$ & $6(3 \%)$ \\
\hline Alogia & $15(8 \%)$ & $39(20 \%)$ & $72(36 \%)$ & $49(25 \%)$ & $24(12 \%)$ \\
\hline Flat affect & $30(15 \%)$ & $71(36 \%)$ & $60(30 \%)$ & $30(15 \%)$ & $7(4 \%)$ \\
\hline \multirow[t]{2}{*}{$\begin{array}{l}\text { According to you, what is the prevalence of negative symptoms at the } \\
\text { onset of psychosis (first episode)? }\end{array}$} & $0-10 \%$ & $11-24 \%$ & $25-49 \%$ & $50-74 \%$ & $>75 \%$ \\
\hline & $3(2 \%)$ & $26(13 \%)$ & $93(46 \%)$ & $61(30 \%)$ & $18(9 \%)$ \\
\hline \multirow[t]{2}{*}{$\begin{array}{l}\text { As part of my clinical practice, it is possible for me to distinguish } \\
\text { between negative symptoms and depression or Parkinsonism }\end{array}$} & Strongly agree & Agree & Undecided & Disagree & $\begin{array}{l}\text { Strongly } \\
\text { disagree }\end{array}$ \\
\hline & $33(17 \%)$ & $117(60 \%)$ & $37(19 \%)$ & $11(6 \%)$ & - \\
\hline \multirow[t]{2}{*}{$\begin{array}{l}\text { How important is the contribution of negative symptoms to functional } \\
\text { outcome in persons with schizophrenia? }\end{array}$} & Unimportant & $\begin{array}{l}\text { Of limited } \\
\text { importance }\end{array}$ & $\begin{array}{l}\text { Moderately } \\
\text { important }\end{array}$ & Important & Very important \\
\hline & - & - & $7(4 \%)$ & $51(26 \%)$ & $142(71 \%)$ \\
\hline $\begin{array}{l}\text { In your practice, do you observe that negative symptoms cause } \\
\text { increased burden for caregivers of patients with such negative } \\
\text { symptoms? }\end{array}$ & $43(22 \%)$ & $136(68 \%)$ & $18(9 \%)$ & $2(1 \%)$ & $1(1 \%)$ \\
\hline \multirow[t]{2}{*}{$\begin{array}{l}\text { Persistent positive symptoms can lead to persistent negative } \\
\text { symptoms }\end{array}$} & Strongly agree & Agree & Undecided & Disagree & $\begin{array}{l}\text { Strongly } \\
\text { disagree }\end{array}$ \\
\hline & $18(9 \%)$ & $81(40 \%)$ & $71(35 \%)$ & $32(16 \%)$ & - \\
\hline
\end{tabular}

Not all respondents answered all questions. Percentages relate to number of responses on each item.

\section{Table 2}

Treatment and assessment of symptoms

\begin{tabular}{|c|c|c|c|c|c|}
\hline Assessment & Always & Frequently & Occasionally & Rarely & Never \\
\hline Do you routinely assess negative symptoms? & $90(45 \%)$ & $87(43 \%)$ & $24(12 \%)$ & $1(1 \%)$ & - \\
\hline If so, do you use any rating scales or any specific questions? & $22(11 \%)$ & $49(24 \%)$ & $57(28 \%)$ & $41(20 \%)$ & $33(16 \%)$ \\
\hline $\begin{array}{l}\text { How effective are atypical antipsychotics for the treatment of } \\
\text { negative symptoms of schizophrenia? }\end{array}$ & $5(3 \%)$ & $27(13 \%)$ & $101(50 \%)$ & $60(30 \%)$ & $9(5 \%)$ \\
\hline $\begin{array}{l}\text { How effective is cognitive-behavioural therapy for the } \\
\text { treatment of negative symptoms of schizophrenia? }\end{array}$ & $1(1 \%)$ & $32(16 \%)$ & $119(60 \%)$ & $44(20 \%)$ & $4(2 \%)$ \\
\hline
\end{tabular}

Not all respondents answered all questions. Percentages relate to number of responses on each item.

biased towards those psychiatrists in this field who are more knowledgeable about negative symptoms. This would suggest the need for a greater effort to increase knowledge and awareness of the importance of persistent negative symptoms among the profession in general.

Despite the limitations of a relatively small sample size, this study represents, to our knowledge, the first survey to examine the state of knowledge and practice patterns of Canadian psychiatrists who work with patients suffering from psychotic disorders.

Our findings suggest the clinical validity and translation of current knowledge of persistent symptoms in clinical practice. However, while psychiatrists emphasised the importance of formally assessing persistent symptoms, few actually carried this out in practice, suggesting that some symptoms may be undetected. Future research may investigate means to increase the use of structured negative symptom assessment in clinical practice.

\section{References}

Andreasen, N. C. \& Olsen, S. (1982) Negative v positive schizophrenia: definition and validation. Archives of General Psychiatry, 39, 789.

Barnes, T. R. \& Paton, C. (2011) Do antidepressants improve negative symptoms in schizophrenia? BMJ, 342, d3371.

Bow-Thomas, C. C., Velligan, D. I., Miller, A. L., et al (1999) Predicting quality of life from symptomatology in schizophrenia at exacerbation and stabilization. Psychiatry Research, 86, 131-142.

Buchanan, R. W. (2007) Persistent negative symptoms in schizophrenia: an overview. Schizophrenia Bulletin, 33, 1013-1022.

Cassidy, C. M., Lepage, M., Harvey, P. O., et al (2012) Cannabis use and anticipatory pleasure as reported by subjects with early psychosis and community controls. Schizophrenia Research, 137 $39-44$

Corcoran, C., Kimhy, D., Parrilla-Escobar, M., et al (2011) The relationship of social function to depressive and negative symptoms in individuals at clinical high risk for psychosis. Psychological Medicine, 41, 251-261.

Foussias, G., Mann, S., Zakzanis, K., et al (2009) Motivational deficits as the central link to functioning in schizophrenia: a pilot study. Schizophrenia Research, 115, 333-337. 
Kirkpatrick, B., Fenton, W. S., Carpenter, W. T., et al (2006) The NIMH MATRICS consensus statement on negative symptoms. Schizophrenia Bulletin, 32, 214-219.

Lehman, A. F., Kreyenbuhl, J., Buchanan, R. W., et al (2004) The Schizophrenia Patient Outcomes Research Team (PORT). Schizophrenia Bulletin, 30, 193-217.

Malla, A. K., Norman, R., Manchanda, R., et al (2002) One year outcome in first episode psychosis: influence of DUP and other predictors. Schizophrenia Research, 54, 231.

Malla, A. K., Bodnar, M., Joober, R., et al (2011) Duration of untreated psychosis is associated with orbital-frontal grey matter volume reductions in first episode psychosis. Schizophrenia Research, $125,13-20$

Milev, P., Ho, B. C., Arndt, S., et al (2005) Predictive values of neurocognition and negative symptoms on functional outcome in schizophrenia: a longitudinal first-episode study with 7-year followup. American Journal of Psychiatry, 162, 495-506.

Möller, H. J. (2003) Management of the negative symptoms of schizophrenia. CNS Drugs, 17, 793-823.

Möller, H. J. (2007) Clinical evaluation of negative symptoms in schizophrenia. European Psychiatry, 22, 380-386.

Perlick, D., Rosenheck, R., Kaczynski, R., et al (2006) Special section on CATIE baseline data: components and correlates of family burden in schizophrenia. Psychiatric Services, 57, 1117-1125.

Rector, N. A. \& Beck, A. T. (2001) Cognitive behavioral therapy for schizophrenia: an empirical review. Journal of Nervous and Menta Disease, 189, 278-287.

Wykes, T., Steel, C. \& Everitt, B. (2008) Cognitive behavior therapy for schizophrenia: effect sizes, clinical models, and methodological rigor. Schizophrenia Bulletin, 34, 523-537.

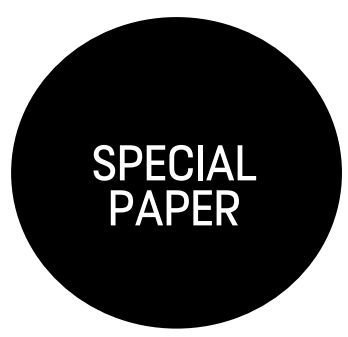

\title{
Psychosocial research with children in Iraq: current health practice and policy in a context of armed conflict
}

\author{
Abdul Kareem Al Obaidi, ${ }^{1}$ Tim Corcoran ${ }^{2}$ and Leslie Scarth ${ }^{3}$
}

'Visiting Scholar, Institute of International Education, New York, USA, email kareemo gmail.com

${ }^{2}$ Victoria Institute, Victoria University, Melbourne, Australia

${ }^{3}$ Consultant Child and Adolescent Psychiatrist, Edinburgh, UK
There is a need to show how psychosocial issues affect children in conflict areas like Iraq. Raising knowledge and awareness of children's mental health status in Iraq has been difficult and the knowledge base has been limited by the shortage of resources, international sanctions and the isolation of Iraqi scholars. Many obstacles to research in Iraq exist but an agenda should be developed emphasising the need for high-quality contextualised psychosocial research. Health researchers in the country need to clarify basic population parameters and to provide culturally appropriate, evidence-based interventions for practitioners.

Much attention has been paid to researching children affected by war and violent conflicts. Major areas of study explore the impact of war on children's health, including the relationship between experiences of conflict and mental health. People in conflict situations experience many psychosocial problems (e.g. personal isolation, interpersonal stress). However, communities rarely have capacity (e.g. mental health resources) to counteract such adverse circumstances. Research can aid in the evaluation of intervention programmes and influence both policy development and future practice, but logistics, methodological and ethical issues, as well as difficulties in measuring intervention effectiveness, present ongoing challenges for researchers in conflict zones. These issues are particularly concerning when researching children (Sondheimer \& Rey, 2012).

Recent social and political instability in Iraq presents a particular dilemma for scholars and investigators. War, economic sanctions and the departure of health professionals during the dictatorship destroyed the country's social service infrastructure. Moreover, after the 2003 war, direct death threats made against those with higher education, perceived as either powerful or wealthy, or both, has reduced the availability of teachers in tertiary education in particular, contributing to the collapse of research activity. This has led to the loss of the scientific research base for social studies in the community, particularly the evidence base for children's health and education services. The psychosocial status of Iraqi children and adolescents is substantially affected by the current environment, which undermines best practice and evidence-based interventions. The need remains to show how psychosocial issues affect health practices and policies involving children in conflict areas like Iraq.

\section{Children's psychosocial issues as a research arena in Iraq}

Various factors contribute to child development and psychosocial well-being (e.g. socioeconomic status, educational attainment). Investigation of these issues is a challenge in both peaceful and conflict areas. Globally, child and adolescent mental health problems present high demands on care services in the face of diminishing resources (Belfer, 2008).

Raising knowledge and awareness of children's mental health status in Iraq has been difficult due to unsystematic coverage of the topic in the literature. While there is some interest in scientific exploration, its scope is limited. For example, it is difficult to source publications targeting childhood mental health prior to 2003. Factors like the 